\title{
Harald Frøshaug og sosialpsykiatrien i Norge
}

\begin{abstract}
Sammendrag
Harald Frøshaugs navn er knyttet til Dikemark sykehus, Oslo kommunes psykiatriske sykehus i Asker. Her fikk han sin skolering i naturvitenskapelig forskning fra overlegen Rolv Gjessing (1887-1959), som var internasjonalt kjent for sine studier over periodisk katatoni ved schizofrene tilstander.

Den annen verdenskrig førte med seg mange oppgaver for legene i psykiatrifeltet. Behovet for nye behandlingsopplegg og teorier ble merkbare. Som enkelte andre rettet Frøshaug blikket mot engelsk og amerikansk psykiatri, særlig de psykoanalytisk orienterte retningene. Da han overtok ledelsen av kvinneavdelingen ved Dikemark sykehus i 1949, var tiden inne for å sette nye metoder ut i praksis.
\end{abstract}

Carl Severin Albretsen Kalkfjellet 13

1387 Asker

Harald Frøshaug (1906-78) har neppe fått den plass han fortjener i norsk psykiatrihistorie. Han var blant de aller første som introduserte sosialpsykiatri som felt i Norge. I denne artikkelen har jeg hoved-

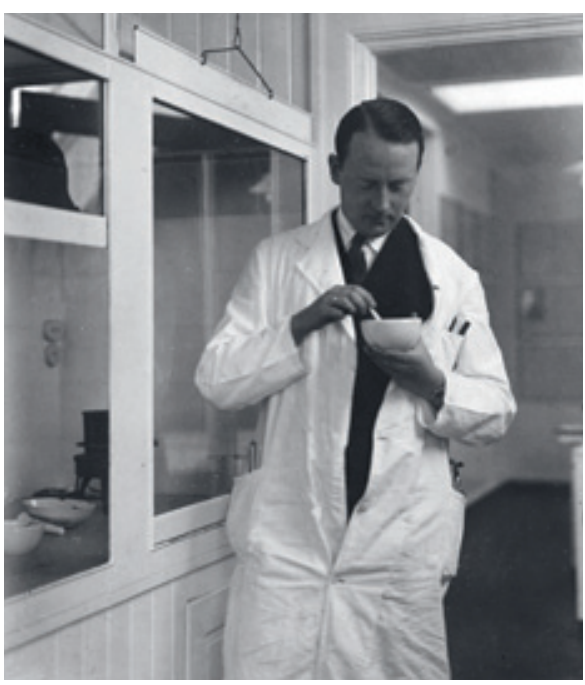

Harald Frøshaug gransker en laboratorieprøve. Begge foto Dikemark museum sakelig hentet informasjon fra hans 49 foredrag fra årene 1935-77 (1). Ved Dikemark sykehus hadde man i 1930-årene mange kroniske pasienter som var preget av uro og urenslighet. En ny metode med insulinsjokk innfridde ikke psykiatriens store forventninger (Om insulin og cardiazolshockbehandling av schizofrene psykoser, foredrag i Dansk psykiatrisk forening november 1937 (1)).

Krigssituasjonen i vårt land skapte store utfordringer. Frøshaug var ansatt ved Psykiatrisk avdeling, Ullevål sykehus der de behandlet 142 kvinner med krigspsykose. I september 1940 holdt Frøshaug foredrag om dette materiale ved Norsk psykiatrisk forenings årsmøte (Om «krigspsykoser» (1)). Godt halvparten av disse pasientene var nye tilfeller. Mange hadde flyktet fra Oslo i aprildagene og havnet i ukjente omgivelser. Atskillelsen fra hjemmet og alle ryktene skapte stor usikkerhet. Tilstanden var preget av forvirring og depresjon. Hos de fleste kom det full oppklaring etter et par uker uten noen spesifikk behandling. Pasienter som var kjent ved avdelingen fra før, var lite preget av krigssituasjonen.

Krigen skapte mange oppbrudd og tragedier, og psykiatrien fikk nye og tunge oppgaver. Dette fortsatte etter krigens slutt. Som fengselslege ved Ilebu fangeleir i Bærum etter freden i 1945 kom Harald Frøshaug i kontakt med en rekke nordmenn som hadde fătt en dom for landssvik. De tidligere høyere pamper i Nasjonal Samling (NS) kunne fortsatt utøve sin makt i fangeleiren fordi de ansatte var i mindretall og uten tidligere erfaring med fanger. Mange av de øvrige fangene var lamslåtte og usikre på sin fremtid. Frøshaug oppfattet dem som harmløse småborgere uten noen tidligere kriminalitet. Det var først og fremst de unge frontkjemperne som fanget hans interesse. Frøshaug mente at sosiale og politiske forhold hadde gjort disse menn til ofre for nazistagitasjonen (2). Det var i alt 5000 nordmenn som hadde gjort tjeneste på Østfronten. Av dem hadde 1000 mann falt og 1800 blitt såret. Frøshaug mente de unge frontkjemperne var et positivt utvalg som det var viktig å få rehabilitert.

\section{Inspirasjon}

Før Harald Frøshaug ble overlege ved Dikemark sykehus hadde han besøkt psykiatriske institusjoner i Europa og USA. Disse erfaringene samt litteraturstudier overbeviste ham om at psykiatrien alltid hadde vært sosialt innstilt. Faget måtte både ta hånd om det enkelte mennesket og dets miljø. Ingen behandling kunne bli vellykket uten at de sosiale forhold hjemme var stabilisert før utskrivningen. I et foredrag august 1950 (Streiftog i moderne psykiatri (1)) mente Frøshaug at dette var grunnen til at de fleste psykiatriske institusjoner hadde opprettet stilling for sosionom. I definisjonen av sosialpsykiatri fulgte Frøshaug professor i psykiatri ved Cornell University Thomas Rennie: Sosialpsykiatri er studiet av etiologi og dynamikk hos mennesker sett i deres totale miljø (Forelesninger i sosialpsykiatri, februar 1958 (1) ). Pasientens opphold i psykiatriske sykehus burde være en trening i sosialt liv (3). Frøshaug ville integrere psykiatri, sosiologi og antropologi og ansatte en ung sosiolog, Yngvar Løchen (1931-98) ved sin avdeling. Løchens doktorgrad, Idealer og realiteter i et psykiatrisk sykehus (4), stammer fra denne tiden. Denne avhandlingen åpnet et nytt fagfelt i Norge, medisinsk sosiologi. Ansettelsen av Løchen viser hvor åpen Frøshaug var for å inkludere andre perspektiver.

Frøshaug kjente godt til psykoanalysen. Harry Stack Sullivan (1892-1949) var sentral. Alle legene ble oppfordret til å sette seg inn i Sullivans bok The interpersonal theory of psychiatry (5). Studien som psykiateren Alfred Stanton og sosiologen Morris Schwartz foretok i et psykiatrisk sykehus ved Chestnut Lodge Sanitarium i USA gjorde et sterkt inntrykk på Frøshaug. De fant at uenighet mellom fagfolk om behandlingen kunne føre til uro hos de aktuelle pasientene (6).

Den britiske psykiater Maxwell Jones fikk mot slutten av den annen verdenskrig den vanskelige oppgaven å rehabilitere store grupper av soldater med psykiske plager (7). Han manglet trent personell og valgte et opplegg med store og små terapeutiske grupper.

\section{Hovedbudskap}

- Harald Frøshaug startet med ettervern for psykiatriske pasienter

- Han inviterte kjente psykiatere fra utlandet til seminar

- Han reorganiserte det psykiatriske sykehus

- En egen spesialskole for sykepleiere ble opprettet under hans ledelse 


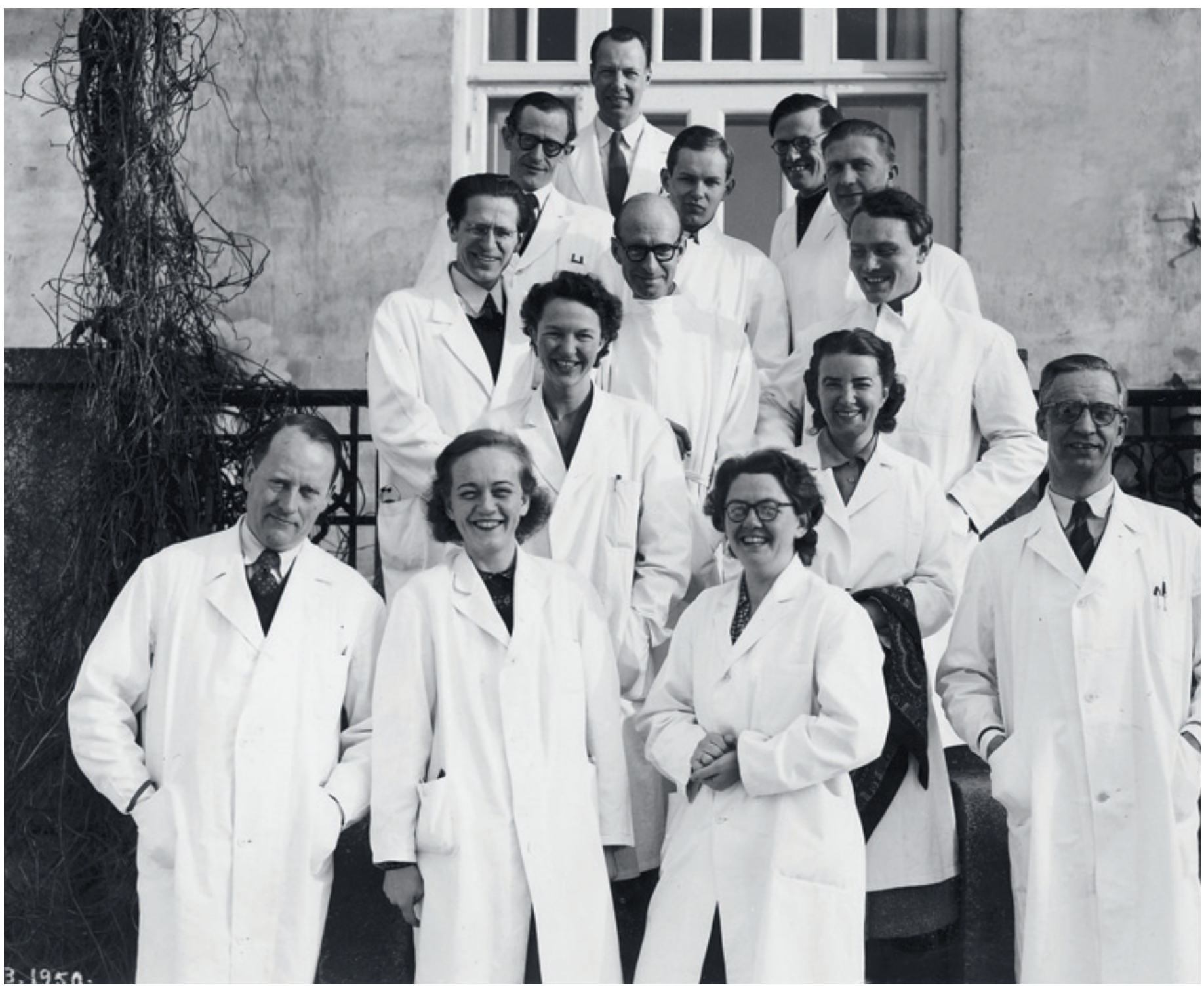

Overlegene Harald Frøshaug (til venstre) og Nils Berner Johannessen flankerer unge medarbeidere ved Dikemark sykehus

Dette viste seg å være effektivt. I tillegg fikk han naboskapet til å gi soldatene småjobber, noe som ga dem følelse av å bli akseptert. Med denne bakgrunn startet han i 1947 en rehabiliteringsenhet, Belmont Hospital (senere Henderson Hospital) i nærheten av London. Han tok inn pasienter uten arbeid og med liten utdanning, alle preget av en personlighetsforstyrrelse. Dagen i avdelingen startet med et fellesmøte ledet av en erfaren pasient, siden var det huslige oppgaver samt deltakelse i ulike smågrupper (8). Jones erfaringer fikk også stor betydning ved etableringen av det terapeutiske samfunn ved Ullevål sykehus i 1959 (9). Harald Frøshaug besøkte Belmont i 1953 og inviterte Maxwell Jones som gjesteforeleser til Dikemark-seminaret i 1966 (10).

\section{Dikemark}

Det var mye å ta fatt på da Frøshaug ble overlege ved Dikemark sykehus. En omorganisering var påkrevd. Pleierne arbeidet fra kl 0630 om morgenen til kl 19 om kvelden.
De kjente rutinene, men manglet formell faglig kompetanse. Man ønsket en fordobling av utdannede sykepleiere. Oslo kommunes helsetjeneste var sterkt presset etter krigen. Mange flyktninger fra de nedbrente distrikter i Nord-Norge var kommet til. I 1948 ble Aker kommune innlemmet i Oslo med sine180 000 innbyggere. Avdelingene ved Dikemark sykehus trengte i høy grad en oppussing. Det var behov for nye betjeningsboliger og nybygg for kroniske pasienter. Frøshaug mente man måtte opprette en innleggelsessentral i Oslo. I tillegg burde byen etablere en psykiatrisk poliklinikk og en egen barneavdeling (Redegjørelse angående innleggelses- og behandlingsforholdene for sinnsyke i Oslo, foredrag for Overlegerådet ved Oslo kommunale sykehus juni $1956(1))$.

I 1955 var det 900 pasienter fordelt på kvinne- og mannsavdelingene ved Dikemark sykehus. 19 leger var i virksomhet, et relativt stort antall etter norske forhold den gang. En sosionom var ansatt ved hver avdeling, bare kvinneavdelingen hadde klinisk psykolog. Leger som ønsket spesialisering i psykiatri, ble fristet av «aksen» Dikemark-Ullevål. Etter to år ved en avdeling i Asker fikk de ett år i Oslo ved en psykiatrisk klinikk - et nåløye i spesialiseringen.

I desember 1957 holdt Frøshaug foredraget Gruppebehandling av kronisk schizofrene i Stockholm (1). Her la han frem de første resultater etter omorganiseringen av avsnittet Granli. Denne bygningen var blitt pusset opp i 1954. I lyse omgivelser og med nye møbler fikk pasientene nå praktiske oppgaver i huset. Den tradisjonelle passiviteten skulle vekk. En nyansatt ergoterapeut hjalp dem med håndarbeid. Gymnastikk ble ledet av en mensendiecklærer, og det ble arrangert fester om kveldene. Atmosfæren i avsnittet ble mer åpen og fri. Betjeningen fikk sine daglige oppklaringsmøter der psykologen var moderator. Disse vesentlige forandringene ble nesten glemt da de nye medikamentene økte behand- 


\section{Harald Frøshaugs}

(1906-78) karriere

- Kandidat, assistentlege Dikemark sykehus 1931-32

- Reservelege Dikemark sykehus 1933-38

- Reservelege Psykiatrisk avdeling, Ullevål sykehus 1938-43

- Kandidat Nevrologisk avdeling, Rikshospitalet 1944-45

- Lege llebu fengsel 1945-47

- Avdelingslege Dikemark sykehus 1948-49

- Overlege Kvinneavdelingen, Dikemark sykehus 1949-74

- Administrerende direktør Dikemark sykehus 1951-62

- Spesialist i psykiatri 1949

- Formann Norsk psykiatrisk forening 1948-50

- Formann Norsk forening for mentalhygiene

- Formann Norges kristelige legeforening 1949

- St. Hallvard-medaljen, Oslo kommune 1974

- Ridder av 1. klasse av St. Olavs orden 1967

lingsmulighetene i de psykiatriske sykehusene.

Frøshaug fikk gjennomført at hver bygning ved kvinneavdelingen skulle ha pasienter som hadde nytte av samme behandlingsopplegg. Han delegerte oppgaver til unge leger og psykologen. Den viktigste nye enheten ble opprettet for unge pasienter med psykotiske tilstander (11). Avsnitt for kroniske nevroser startet i februar 1959 med allmannamøter (fellesmøter) med Frøshaugs godkjenning. Han var ofte til stede når de forskjellige avsnittene diskuterte behandlingsopplegget for nye pasienter.

Dikemark hadde en faglig tiltrekningskraft på grunn av sine årlige seminarer. Disse var initiert av Harald Frøshaug. Det første seminaret ble holdt i 1955. Ledende psykiatere fra Europa og Amerika holdt innledende foredrag (10). Etterpå ble det diskutert i smågrupper.

Dikemark sykehus hadde i en årrekke hatt kurs for sine pleiere. Frøshaug intensiverte dette arbeidet og tok kontakt med Norsk sykepleierforbund for å få i gang en spesialundervisning i psykiatri for sykepleiere. Han fikk oppført sykepleierskolen på Dikemark i 1954, og her fikk sykepleiere og hjelpepleiere i mange år fremover sin videreutdanning. Frøshaug deltok selv i undervisningen og var særlig opptatt av holdningen som personalet skulle ha overfor pasientene.

\section{Ettervernet}

Kvinneavdelingen ved Dikemark sykehus var landskjent for sitt ettervernssystem (12). Harald Frøshaug startet denne viktige virksomheten i 1952. Hver pasient som var ferdigbehandlet i Asker, fikk avtale om en videre kontakt med sin terapeut ved et kontor i Oslo. Alle legene hadde således en unik mulighet til å følge sine pasienter i tiden etter utskrivning til hjemmet. En ettermiddag ukentlig reiste legene inn fra Dikemark og jobbet ved ettervernskontoret. Alle ble overbevist om at en kontinuitet var vesentlig i psykiatrisk arbeid. Det organiserte ettervernet førte til at pasienten fikk adekvat medisin og legene vedvarende kontakt med de pårørende. Et slikt arbeid kunne forhindre residiv $(12,13)$. Ettervernet utvidet seg sterkt. Det fikk sine faste klubber, ettervernshjem, dagsenter samt vernet arbeidsvirksomhet. Ettervernet ble egen avdeling i 1971 og i 1993 det første distriktspsykiatriske senteret i Oslo.

\section{Planer i samtid og fremtid}

I 11 år hadde Harald Frøshaug ansvar for både kvinneavdelingen og hele Dikemark sykehus. Dette gjorde det sannsynligvis lettere for ham å få gjennomført forandringer, men arbeidsdagen ble lang med faglige og administrative møter både på Dikemark og i Oslo. I foredraget Psykiateren, pasienten og samfunnet i Det norske studentersamfund i februar 1958 ønsket Frøshaug mentalhygiene som fag i skolen (1). Familiekontorene, som ble drevet av kristelige organisasjoner, var en del av dette arbeidet. De store byene burde desentraliseres slik at bydelene kunne bli selvforsynte. De psykisk syke burde få hjelp på et tidlig tidspunkt ved en poliklinikk. Daghospitaler ville bli knyttet til det psykiatriske sykehuset.

I foredraget Langtidspasienter fra 1970 (1) regnet Frøshaug med at psykiatrien i Oslo ville bli sektorisert, og han antydet sektorer på ca. 125000 mennesker. En samfunnspsykiatrisk klinikk burde plasseres midt i disse enhetene (Psykiatriens oppgaver og nye ansvarsområder $i$ dag og i fremtiden, foredrag ved årsmøte på Modum Bads Nervesanatorium 1970) (1). Etter at Harald Frøshaug sluttet ved Dikemark sykehus, fordypet han seg i arbeidet med sine pasienter (14).

Etter hans død instituerte Dikemark sykehus årlige forelesninger kalt Harald Frøshaugs minneforelesning. Assisterende overlege Per Vaglum (f. 1938) holdt det første i 1981. Deretter ble det holdt årlige forelesninger inntil de av økonomiske årsaker tok slutt i 1995 (10).
Eldbjørg Nåheim Eien skal ha stor takk for hjelp til å finne relevant litteratur.

Oppgitte interessekonflikter: Ingen

Litteratur

1. Foredrag av Harald Frøshaug 1935-77. Bd. 1-6. Stensil. Asker: Dikemark sykehus, 1975-77.

2. Frøshaug H. A social-psychiatric examination of young front- combatants. Acta Psychiatr Neurol Scand 1955; 30: 443-65.

3. Frøshaug H. Psykiatri i et sosialt perspektiv. Tidsskr Nor Lægeforen 1964; 84: 264-5.

4. Midre G. Yngvar Løchen. I: Arntzen JG, red. Norsk biografisk leksikon. Bd. 6. Oslo: Kunnskapsforlaget, 2003

5. Sullivan HS. The interpersonal theory of psychiatry. New York, NY: Norton, 1953.

6. Stanton AH, Schwartz MS. The mental hospital. New York, NY: Basic Books, 1954.

7. Jones M. Group work in mental hospitals. $\mathrm{Br}$ J Psychiatry 1966; 112: 1007-11.

8. Jones M. Social psychiatry in the community, in hospitals, and in prisons. Springfield, Il: Charles C. Thomas, 1962.

9. Thomstad H, Gydal M. Det terapeutiske samfunn 1: Alnæs R, Johnsen G, red. Psykoterapi. Bd. 2. Oslo: Fabritius, 1968

10. Zeiner-Henriksen K, Gravem A, Mamen HC, red. De siste årene? Dikemark sykehus 1955-1995. Asker: Dikemark sykehus, 1995

11. Frøshaug H, Sirnes TB, Stenstad F. Intensive treatment program in a mental hospital. Acta Psychiatr Scand Suppl 1963; 39: 120-33.

12. Kringlen E. Norsk psykiatri gjennom tidene. Oslo: Damm, 2007.

13. Digranes A, Frøshaug H. Erfaringer fra psykiatrisk eftervernsarbeid. Nord Med 1961; 66: 1059-61.

14. Johnsen G. Harald Frøshaugs betydning for norsk psykiatri. Kirke og kultur 1982; 87: 51-6.

Manuskriptet ble mottatt 8.12. 2008 og godkjent 5.11. 2009. Medisinsk redaktør Anne Kveim Lie. 